\title{
An Empirical Research on SMC in an Extended Enterprise Environment
}

\author{
Jiayin $\mathrm{Qi}^{1}$, Huaying Shu ${ }^{1}$, and Huaizu $\mathrm{Li}^{2}$ \\ 1 Economics and Management School, Beijing University of Posts and \\ Telecommunications, 10 Xi Tu Cheng Road, Haidian District, Beijing, \\ China, 100876 \\ mailto:ssfqjy@263.net, \\ shuhy@bupt.edu.cn, \\ WWW home page: http://Www.sem.bupt.cn \\ 2 Professor, School of Management \\ $\mathrm{Xi}$ 'an Jiaotong University \\ Xi'an, Shannxi, China, 710049 \\ Email: Hzli@xjtu.edu.cn
}

\begin{abstract}
There are few empirical researches and applications of SMC models for shortage of customer data and their complexity. Choosing IT distribution market industry as background, an empirical research is done in this paper. The conclusion is that SMC models do work in IT distribution market industry. They have relatively high prediction accuracy. Also, the revise advice for SMC is put forward to meet different types of customer behaviors.
\end{abstract}

\section{Introduction}

SMC models are a group of models to forecast customer's buying behaviors and were provided in 1987 by D.C. Schmittlein, D.G. Morrison and R. Colombo [1]. There are few empirical researches and applications of SMC models for shortage of customer data and their complexity [2,3]. If SMC models are proved to be true, they are very valuable in designing analytical CRM (Customer Relationship Management) systems.

Choosing IT distribution market industry as background, an empirical research is done in this paper. Digital China is the biggest company in China's IT distribution market. Through random sample, we obtained 1324 customers' consumption records

Please use the following format when citing this chapter:

Qi, J., Shu, H., Li, H., 2006, in International Federation for Information

Processing, Volume 205, Research and Practical Issues of Enterprise Information Systems, eds.

Tjoa, A.M., Xu, L., Chaudhry, S., (Boston:Springer), pp.749-754. 
to determine the parameters of SMC models. Then, we selected 331 customers to test SMC models. The conclusion is that SMC models do work in IT distribution market industry. They have relatively high prediction accuracy. The application of SMC models in CRM is discussed in details. Also, the modification advice for SMC is put forward to meet different types of customer behaviors.

\section{Hypotheses Development}

SMC models have four models to calculate the following variables in customer behavior prediction:

1) The description on current customer's active degree; the customer's active degree is a variable describing the probability of customers' purchase; the higher the value is, the larger the customer' possibility will be.

2) Purchase frequency within the next trading period " $\mathrm{T} 1$ ";

3) The probability for customers to purchase $K$ times within the next period "T2"

4) Expected dollar volume in each purchase.

For the limitation of the paper, the exact models are not presented in the paper; anyone who has interesting can find them in Schmittlein et al., [1,2].

We consider that SMC models are suitable for the forecasting of customer's buying behavior in IT distribution market industry, that is:

Hypothesis 1: The customer's active degree model of SMC models comes into existence in IT distribution market.

Hypothesis 2: The expected purchases number model of SMC models comes into existence in IT distribution market.

Hypothesis 3: The probability of purchasing appointed number times during a period of time in the future model of SMC models comes into existence in IT distribution market industry.

The defect lies in that the expected future dollar volume model is not verified in this paper due to data resources.

\section{Research methodology}

\subsection{Data collection}

Digital China is a first class IT distribution enterprise in China. Our research selected its customer in the Beijing area as a sample to check out SMC models' applicability in the IT distribution field. To validate the efficiency of SMC models in IT distribution market industry, we divide the customers sample pool into two parts: customer sample I and II. The first one's final observation time is October in 2001 and the other one's final observation time is November in 2001. In other words, customers sample I traces from the initial time to October, 2001, while Customers sample II trace from the initial time to November, 2001. In order to 
judge the applicability of the SMC models, we analyze customer sample I using SMC models to forecast whether the customer will make purchase in November and how many times the purchases happen, then we compared the results with the actual situation in Customers sample II. The total sample is 331 customers.

\subsection{SMC models validation analysis}

Using Schmittlein and Peterson's 2-step parameter definition method [2] to analyze the data getting from the customer sample I, we obtain the result that $r=1.66, \alpha=3.58, s=0.33, \beta=0.5$, then using the corresponding model in SMC, we get the concrete value of each customer's active degree, expected purchase number and the probability to purchase certain times in November, 2001. Through the comparison of the forecasting value and actual value, we testified the applicability of SMC model in IT distribution market industry. In other words, the former three assumptions are validated.

Customer's active degree model can be used to forecast the customer's buying behavior in IT distribution market

Compared the 311 customers' forecasting active degree in November, 2001 with their true buying record in sample II , it is found that when the forecasting active degree is below 0.600 , the actual purchase hardly happens. With the increase of the customer's active degree, the possibility of happening 1 or 2 times purchase increases greatly. When the customer's active degree equals to 1 , the possibility of purchase once is the biggest, and so does the possibility of purchase twice. These analytical results can be seen in Table 1:

Table 1. The effect of customer's active degree model in forecasting customer's buying behavior

\begin{tabular}{|c|c|c|c|c|c|c|c|}
\hline \multirow{3}{*}{$\begin{array}{l}\text { The } \\
\text { Forecasting } \\
\text { value of } \\
\text { customer's } \\
\text { active } \\
\text { degree in } \\
\text { Nov. } 2001\end{array}$} & \multirow{3}{*}{$\begin{array}{l}\text { Sample } \\
\text { Volume }\end{array}$} & \multicolumn{6}{|c|}{ Customer's actual purchase number in November, 2001} \\
\hline & & \multicolumn{2}{|c|}{0} & \multicolumn{2}{|c|}{1} & \multicolumn{2}{|c|}{2} \\
\hline & & $\begin{array}{l}\text { Sample } \\
\text { Volume }\end{array}$ & $\begin{array}{c}\text { Ratio } \\
(\%)\end{array}$ & $\begin{array}{l}\text { Sample } \\
\text { Volume }\end{array}$ & $\begin{array}{c}\text { Ratio } \\
(\%)\end{array}$ & $\begin{array}{l}\text { Sample } \\
\text { Volume }\end{array}$ & $\begin{array}{c}\text { Ratio } \\
(\%)\end{array}$ \\
\hline$[0,0.600]$ & 152 & 151 & 99.34 & 1 & 0.66 & 0 & 0 \\
\hline $\begin{array}{l}(0.600 \\
1.000)\end{array}$ & 75 & 61 & 81.33 & 13 & 17.33 & 1 & 1.33 \\
\hline 1.000 & 104 & 55 & 53.40 & 43 & 40.78 & 6 & 5.83 \\
\hline Total & 331 & 267 & 80.91 & 57 & 16.97 & 7 & 2.12 \\
\hline
\end{tabular}

It can be confirmed that 0.600 is the critical value between the active customers and the inactive customers. Below this value, the customers are inactive which means there is little chance left for the enterprise to trade with these customers, it is safe to say that this group of customers is already lost. And above this value, the 
customers are active, the higher the active degree of the customers is, the greater the possibilities and times of the purchase are. Thus, the critical value of the customer's active degree is a very important way to forecast customer's buying behavior. If the enterprise prepares to trade with some customers, the managers must be sure that these customers' active degree are higher than the critical value. So, customer's active degree is a necessary condition for enterprise to choose aim customer in the future.

Therefore, the active degree model in SMC models can be applied at the customer's buying behavior forecasting in the IT distribution industry, so hypothesis 1 is demonstrated.

The expected purchase number model can be used to forecast the customer's buying behavior in IT distribution market

Through the comparison of the forecasting value of customer's expected purchase number based on customer sample I and the actual purchase number in customer sample II, we validate the validity of forecasting the customer's future buying behavior using the SMC's expected purchase number model. The prediction details are shown in Table 2:

Table 2. The effect of customer's expected purchase number model in forecasting customer's buying behavior

\begin{tabular}{|c|c|c|c|c|c|c|c|}
\hline \multirow{3}{*}{$\begin{array}{l}\text { The forecast of } \\
\text { customer's } \\
\text { expected } \\
\text { purchase } \\
\text { number in } \\
\text { November, } \\
2001\end{array}$} & \multirow{3}{*}{$\begin{array}{l}\text { Sample } \\
\text { Volume }\end{array}$} & \multicolumn{6}{|c|}{$\begin{array}{l}\text { The actual customer's purchase number in November, } \\
\qquad 2001\end{array}$} \\
\hline & & \multicolumn{2}{|c|}{0} & \multicolumn{2}{|c|}{1} & \multicolumn{2}{|c|}{2} \\
\hline & & $\begin{array}{l}\text { Sample } \\
\text { Volume }\end{array}$ & $\begin{array}{l}\text { Ratio } \\
(\%)\end{array}$ & $\begin{array}{l}\text { Sample } \\
\text { Volume }\end{array}$ & $\begin{array}{l}\text { Ratio } \\
(\%)\end{array}$ & $\begin{array}{l}\text { Sample } \\
\text { Volume }\end{array}$ & $\begin{array}{l}\text { Ratio } \\
\text { (\%) }\end{array}$ \\
\hline$[0.000,0.300)$ & 169 & 167 & 98.82 & 2 & 1.18 & 0 & 0 \\
\hline$[0.300,0.500)$ & 52 & 41 & 78.85 & 11 & 21.15 & 0 & 0 \\
\hline$[0.500,0.800)$ & 85 & 65 & 76.47 & 18 & 21.18 & 2 & 2.35 \\
\hline$[0.800,1.000)$ & 35 & 13 & 37.14 & 22 & 63.86 & 0 & 0 \\
\hline$[1.000,1.700]$ & 13 & 5 & 38.46 & 3 & 23.08 & 5 & 38.46 \\
\hline Total & 330 & 267 & 80.91 & 56 & 16.97 & 7 & 2.12 \\
\hline
\end{tabular}

From Table 2, we can see that the possibility of none purchase becomes less when customers' expected purchase number increase, in other words, the purchase probability becomes larger. When the forecasting value comes to a certain value, customers incline to make more purchase. What's more, for any customer sample, we can find a critical value of customer's expected purchase number. Under this critical value, a customer's real purchase chance in future is very little. Thus, for most customers, if there is a purchase, the forecasting value of customer's expected purchase number must be higher than the critical value. Just like the critical value of customer's active degree, this condition can be recognized as another necessary condition to forecast customer's buying behavior. 
Therefore, the expected purchase number model in SMC models can be applied at the customer's buying behavior forecasting in IT distribution industry, so hypothesis 2 is demonstrated.

The probability of purchasing appointed number times during a period of time model is validated in IT distribution market industry

We can get the probability $P\left[\mathrm{x}^{*} \mid r, \alpha, s, \beta, x, t_{1}, t_{2}, t^{*}\right]$ of any customers in customer sample I with $x^{*}$ times trading happened at the time period $t^{*}\left(t^{*}\right.$ represents any time period after $t_{2}$ ). The results show that the probability of purchasing 3 times is zero, and the chance of buying twice is small also. With the increase of $x^{*}$, this value decreases. This is corresponding to the actual situation. Take the time period of November 2001 as an example. In this month, the trading frequency of customers are all below 3 , in other words, the probability of purchasing 3 times is zero, there are only 7 customers whose purchase frequency is equal to 2 , which takes up $2.12 \%$ of the customer sample, there are 56 customers whose trading frequency is equal to 1 , accounted for the $16.97 \%$ of the customer sample and customers without trading take up the largest portion at $80.81 \%$. With the extending of the time $t^{*}$, this value becomes greater, this is an obvious result. This illustrates that this model is suitable for the IT distribution market. From the expression of formula (9), we can clearly see that $P\left[\mathrm{x}^{*} \mid r, \alpha, s, \beta, x, t_{1}, t_{2}, t^{*}\right]$ is the product of two numbers which both between the value of 0 and 1 . Thus, it is a comparatively small positive number. Through the one by one analysis of the customers' data sample I, we tested this point. The model based on the Digital China's customers' data is consistent with the theoretical model, hence we validate the fact that this model can be applied into IT distribution market, in other words, hypothesis 3 comes into existence.

Because this forecasting value is relatively small in most cases, it is not suitable for enterprise to use. So we advise to use customer's active degree and the customer's expected purchase number as the two important indexes to forecast customer's buying behavior.

\section{Conclusions}

Through empirical research, this paper proves the applicability of SMC models in IT distribution market, but these models cannot necessarily be applied to all industries. A key factor that whether SMC models could be applied is that whether Poisson distribution could be used to describe the customer buying behavior in that industry. In fact, customer's buying behavior is close to time nonhomogeneous Poisson distribution, and this case is more usual in fact. For SMC models' wide applicability, it is surely a research trend to use time nonhomogeneous Poisson distribution to substitute time homogenous Poisson distribution, which could greatly expand the range of applicability. 


\section{Acknowledgements}

Research of this paper is funded by the National Natural Science Foundation of China (Project No.70371056) and the Key Laboratory of Information Management \& Information Economy of Ministry of Education of the People's Republic of China.

\section{References}

1. D.C. Schmittlein, D.G. Morrison, and R. Colombo, Counting Your Customers: Who Are They and What Will They Do Next? Management Science 33(1), 1-24 (January 1987).

2. D.C. Schmittlein and R.A. Peterson, Customer Base Analysis: An Industrial Purchase Process Application, Marketing Science 13(1), 41-67 (Winter 1994).

3. Werner J Reinartz, V Kumar. On the Profitability of Long-life Customer in a Noncontractual Setting: An Empirical Investigation and Implication for Marketing, Journal of Marketing 64(4), 17-35 (October 2001). 